\title{
The distinctive nature of adenocarcinoma of the lung
}

This article was published in the following Dove Press journal:

OncoTargets and Therapy

2 September 2015

Number of times this article has been viewed

\author{
Giandomenico Roviello \\ Department of Molecular and \\ Translational Medicine, University \\ of Brescia, Brescia, Italy
}

\begin{abstract}
In recent years, many personalized treatments have been developed for NSCLC (non-small-cell lung cancer) patients. Among these, gefitinib, erlotinib, and afatinib are selective epidermal growth factor receptor (EGFR) tyrosine kinase inhibitors for patients with EGFR gene mutations, while crizotinib and ceritinib are two new tyrosine kinase inhibitors directed against the echinoderm microtubule-like protein 4-anaplastic lymphoma kinase translocation. The possibility of these new molecules being used to treat patients without adenocarcinoma histology is notably small. For example, EGFR mutations and anaplastic lymphoma kinase fusion gene rearrangement are rare in patients with squamous cell carcinoma (generally $<1 \%$ ). Additionally, the benefit of targeted treatment approaches in patients with small-cell lung cancer histology is limited. All of these findings highlight the distinctive nature of adenocarcinoma of the lung among all lung cancer subtypes. Unfortunately, to date, less than $15 \%$ of patients with adenocarcinoma of the lung are ideal candidates for these targeted therapies.
\end{abstract}

Keywords: lung cancer, adenocarcinoma, EGFR, ALK

\section{Introduction}

Lung cancer can be considered the most common malignancy and the leading cause of cancer death worldwide. ${ }^{1}$ Generally, there are two major classes of lung cancer: non-small-cell lung cancer (NSCLC) and small-cell lung cancer (SCLC), and they have significant differences in biology, responses to therapy, and prognosis. NSCLC accounts for more than $85 \%$ of all lung cancer cases, and it includes non-squamous cell carcinomas (including adenocarcinoma, large-cell carcinoma, and other cell types) and squamous cell carcinomas. Adenocarcinoma is the most common type of lung cancer in general and in nonsmokers. Adenocarcinoma of the lung is a histologically, biologically, and genetically heterogeneous disease, conditioned by gradual accumulation of various genetic and epigenetic alterations leading to the activation of several molecular pathways and resulting in markedly different responses to the same treatment. A deeper understanding of the complexity of this disease has led to the development of small molecules that target genetic mutations known to play a critical role in the progression of adenocarcinoma to metastatic disease and affect the response of the adenocarcinoma to targeted therapies. Therefore, more recently, for patients with adenocarcinoma of the lung, personalized treatment has become a reality, with the development of many drugs that target specific pathways are altered in this disease. Here, we describe the distinctive nature of adenocarcinoma of the lung in regard to targeted therapies.

\section{Targeting the epidermal growth factor receptor}

The first abnormalities discovered in lung cancer were epidermal growth factor receptor (EGFR) kinase domain mutations. EGFR-HER1 is one of four receptors 
involved in the pathway of epidermal growth factor (EGF) transfer (HER). It is a transmembrane receptor composed of an extracellular binding domain, a transmembrane domain, and an intracellular cytoplasmic domain with tyrosine kinase functionality. ${ }^{2}$ EGFR is activated by specific ligands, such as EGF, transforming growth factor- $\alpha$, amphiregulin, heparinbinding EGF, betacellulin, epiregulin, and neuregulin $2-\alpha$. Ligand binding to the receptor induces a conformational change in the intracellular cytoplasmic domain, which promotes homodimerization as well as heterodimerization with the other HER family members, resulting in tyrosine kinase autophosphorylation and activation. ${ }^{3}$ This activation can promote tumor proliferation, invasion, migration, and neovascularization, which are mediated by the V-Ki-ras2 Kirsten rat sarcoma viral oncogene homolog (KRAS)/murine sarcoma viral oncogene homolog B (B-RAF)/mitogenactivated protein kinase and phosphatidylinositol-3-kinase/ protein kinase B (AKT)/mammalian target of rapamycin pathways. ${ }^{2}$ In 2004, the identification of somatic activating mutations in the EGFR gene was found to be closely linked with favorable clinical responses to EGFR-tyrosine kinase inhibitors (TKIs), and this led to the approval of gefitinib, erlotinib, and afatinib as first-line therapies for patients with lung adenocarcinoma with mutated EGFR. ${ }^{46}$ To date, four mutations in EGFR exons have been identified, and they all involve the kinase domain of EGFR: a point mutation at G719 in exon 18, a deletion of the amino acids $747-750$ in exon 19 , in-frame insertions in exon 20 , and point mutations at L858 and L861 in exon $21 .^{7-9}$ The most commonly observed EGFR mutations are deletions in exon 19 (45\% of patients) and mutations in exon 21 (43\% of patients). ${ }^{10}$ Both these mutations result in activation of the tyrosine kinase domain. ${ }^{7}$ Generally, these mutations more frequently arise in women and in nonsmokers with bronchioalveolar adenocarcinoma histology. ${ }^{11}$ According to race, EGFR mutations are found in approximately $10 \%$ of Caucasian patients and up to $50 \%$ of Asian patients. ${ }^{9}$ Finally, other predictors of response to anti-EGFR-TKIs besides EGFR gene mutations have been reported. Some authors found a correlation between EGFR gene amplification and response to EGFR-TKIs, as tumors with an EGFR gene amplification are frequently associated with coexisting EGFR mutations. ${ }^{12}$ Additionally, the presence of KRAS mutations, which are frequent in smokers, seems to predict a negative response to EGFR inhibitors. ${ }^{13}$

Gefitinib and erlotinib or afatinib are approved selective EGFR-TKIs that should be used as first-line systemic therapy in patients with EGFR-mutated lung cancers in place of standard first-line chemotherapy. ${ }^{4,14,15}$ Although the data on response and progression-free survival (PFS) favor the use of
EGFR-TKIs in patients with EGFR mutations compared to standard chemotherapy, the data on overall survival are not as definitive. ${ }^{14,15}$ Additionally, although small differences in reported toxicities appear to favor one drug over the others, the lack of a direct comparison trial of TKI precludes any definitive conclusions.

Unfortunately, $20 \%-50 \%$ of patients with clinical or biologic predictors of EGFR-TKI sensitivity are resistant to these drugs (primary or de novo resistance) ${ }^{16}$ Primary resistance to TKI therapy is associated with EGFR exon 20 insertions that result in a mutated form of the EGFR protein and with KRAS mutations and anaplastic lymphoma kinase (ALK) gene rearrangements. ${ }^{17}$ Acquired resistance to EGFR-TKIs almost always develops after a median time of approximately 10 months from the initiation of treatment. Different genotypic and histologic mechanisms of resistance have been suggested..$^{18}$ The most common cause of acquired resistance to EGFR-TKIs is the presence of a mutation in the EGFR gene at exon 20, especially the substitution of methionine for threonine at position $790(\mathrm{~T} 790 \mathrm{M})$, which accounts for more than half of such cases. However, several studies have suggested that the T790M mutation may also occur in patients who have not previously received TKI therapy. ${ }^{19,20}$ Other causes of secondary resistance include amplification of the hepatocyte growth factor receptor (MET) receptor tyrosine kinase, KRAS mutations, ALK gene rearrangements and phosphatidylinositol-3-kinase mutations. ${ }^{21}$ Finally, acquired resistance can be associated with histologic transformation from NSCLC to SCLC and with tumor cells undergoing epithelial to mesenchymal transition..$^{22,23}$

To date, there is no consensus on the treatment for patients resistant to EGFR-TKIs. Second-line options include chemotherapy alone or continuation of TKI therapy with delayed chemotherapy. ${ }^{24}$ The addition of chemotherapy with the continuation of prior EGFR-TKI therapy may be another secondline option; however, a recent Phase III study showed that PFS did not significantly improve with the continuation of gefitinib in addition to platinum-based doublet chemotherapy compared to chemotherapy alone. ${ }^{25}$ Other strategies include re-treatment with EGFR-TKI after performing second-line salvage chemotherapy and re-treatment with EGFR-TKI after a drug-free interval. ${ }^{26}$ Finally, these patients may be considered for a clinical trial. ${ }^{26}$ In this setting, second- and thirdgeneration EGFR-TKIs were designed that more potently inhibit EGFR to overcome the resistance provided by the EGFR T790M mutation. The second-generation EGFR-TKIs (dacomitinib, afatinib, and neratinib) have a higher affinity for the EGFR tyrosine kinase domain than first-generation EGFR-TKIs (erlotinib and gefitinib). ${ }^{27}$ Furthermore, the 
second-generation EGFR-TKIs are pan-HER inhibitors that have in vitro activity against the T790M mutation. Unfortunately, although afatinib has been approved as a first-line treatment for advanced NSCLC-harboring activating EGFR mutations, and dacomitinib is under development in the same patient setting, in clinical trials, second-generation EGFR-TKIs (dacomitinib, afatinib, and neratinib) have shown limited activity in patients with acquired resistance to first-generation EGFR-TKIs. ${ }^{28-30}$ The greatest treatment success has been achieved with the combination of afatinib with cetuximab (an anti-EGFR monoclonal antibody) in patients who developed resistance to erlotinib or gefitinib. However, this combination is associated with several adverse effects (overall skin and gastrointestinal adverse effects). Conversely, the third-generation EGFR-TKIs, rociletinib (CO-1686) and AZD9291, have been confirmed to have preclinical activity against lung cancer with the EGFR T790M mutation; this was observed in two recent clinical Phase I-II studies in patients with EGFR-mutated NSCLC associated with the T790M resistance mutation who had experienced disease progression during prior therapy with EGFR-TKIs. ${ }^{31,32}$

\section{Targeting the translocation of the ALK gene}

ALK is a transmembrane receptor tyrosine kinase that is a member of the insulin receptor superfamily. Rearrangements of the ALK gene have been reported in a rare subset of diffuse large B-cell lymphomas and inflammatory myofibroblastic tumors. ${ }^{33,34}$ Echinoderm microtubule-like protein 4 (EML4) is a protein that is encoded by the EML4 gene in humans and is necessary for correct microtubule formation (stabilizes microtubules). More recently, a new gene rearrangement resulting in a fusion gene between EMEL4 and ALK was discovered in NSCLC cells. ${ }^{35}$ This rearrangement was not unique, as several variants have been reported. Generally, they involve the same intracellular tyrosine kinase domain of ALK, but different truncations of EML4. ${ }^{36-39}$ However, their significance in clinical settings is unclear. Nonetheless, ALK rearrangement is a rare event in NSCLC patients; it is generally reported in $2 \%-5 \%$ of adenocarcinomas and in young female patients and nonsmokers and light smokers. ${ }^{40}$ Moreover, this alteration seems to be independent of EGFR and KRAS gene mutations, although they are not mutually exclusive. ${ }^{39,41-45}$ Crizotinib - an inhibitor of ALK, ROS1, and MET tyrosine kinases - is approved by the FDA (US Food and Drug Administration) for patients with locally advanced NSCLC and metastatic NSCLC who are positive for the ALK gene rearrangement. ${ }^{39,46}$ In a randomized Phase III trial involving patients with advanced ALK-positive NSCLC who had received previous platinum-based chemotherapy, crizotinib showed superior efficacy to that of single-agent secondline chemotherapy with pemetrexed or docetaxel. ${ }^{47}$ More recently, a multicenter, randomized, open-label, Phase III study (PROFILE 1014) that compared crizotinib treatment with pemetrexed-plus-platinum chemotherapy showed the superiority of first-line therapy with crizotinib in patients with previously untreated advanced ALK-positive NSCLC. ${ }^{48}$ Unfortunately, most of the patients treated with crizotinib progressed within the first 11 months. ${ }^{47}$ Although, the lack of response in a subset of patients with EML4-ALK rearrangement in the ongoing PROFILE 1,001 study may suggest a potential resistance to ALK inhibition, acquired resistance to crizotinib is well documented. ${ }^{49}$ The acquired mechanisms of ALK inhibition resistance may directly involve ALK rearrangement (ALK gene mutations and ALK gene amplification) or other oncogenic pathways that coexist with ALK rearrangement, which are called "ALK-dominant" mechanisms and ALK "nondominant" mechanisms, respectively. Generally, "ALK-dominant" mechanisms, particularly those involving ALK gene mutations are the most common. To date, almost eight mutations have been described that result in resistance to crizotinib-based therapy (L1196M, C1156Y, 1151Tins, G1202R, S1206Y, F1174C, D1203N, and G1269A). ${ }^{50-52}$ They account for $28 \%$ of cases of resistance to crizotinib. These mutations may involve crizotinib-binding sites or sites distant from crizotinib-binding sites. For example, the mutations G1202R and S1206Y are clustered around the ATP-binding pocket of ALK, and they cause reduced affinity of crizotinib for its binding site on the mutant ALK protein. The mutation L1196M is a gatekeeper that leads to resistance to crizotinib. Finally, the mutation 1151 Tins is distant from the crizotinibbinding site, but decreases the affinity of ALK for ATP. ${ }^{53}$ Another type of acquired mutation is wild-type ALK gene amplification. ${ }^{53}$ In particular, a copy number gain (defined as an increase in the number of copies of the rearranged gene in cancer cells following crizotinib treatment compared to before crizotinib treatment) was detected in $18 \%$ of patients. Finally, crizotinib resistance may be associated with the aberrant activation of a parallel or downstream signaling pathway, including KRAS mutations, marked amplification of KIT, and increased autophosphorylation of EGFR. ${ }^{53,54}$

Ceritinib is a second-generation ALK inhibitor that has been demonstrated to have activity in crizotinib-resistant patients; thus, it is a promising treatment option in this population. Ceritinib was recently approved in patients with ALK-positive metastatic NSCLC with either disease progression or intolerance to crizotinib. ${ }^{55}$ Ceritinib seems to overcome some of the crizotinib resistance mutations (L1196M, 
G1269A, S1206Y, and I1171T). ${ }^{53,54}$ Two ongoing Phase III trials are investigating ceritinib versus standard chemotherapy in previously untreated and previously treated patients with ALK-rearranged NSCLC (ASCEND-4, ASCEND-5). Additionally, in July 2014, alectinib (a highly selective, orally bioavailable ALK inhibitor with tenfold greater potency than crizotinib) was granted approval in Japan for the treatment of patients with recurrent/relapsed ALK rearrangement NSCLC. ${ }^{56}$ Furthermore, more agents (alectinib, ASP3026, and X396) with improved safety, selectivity, and potency are under investigation. ${ }^{57}$ Finally, therapeutic approaches, including crizotinib-based combination therapy and novel agents, such as heat-shock protein 90 (Hsp90) inhibitors, are currently under evaluation. ${ }^{39}$

\section{Other targets}

Angiogenesis plays a fundamental role in tumor growth and metastatic dissemination. Vascular endothelial growth factor (VEGF) is a fundamental regulator of angiogenesis. Bevacizumab (Bev) is a recombinant, humanized, monoclonal antibody against vascular endothelial growth factor that has been approved for the first-line treatment of several solid tumors. It has also been approved by the FDA for the first-line treatment of patients with unresectable, locally advanced, or metastatic non-squamous NSCLC. The use of Bev in these patients is well documented..$^{58}$ Additionally, in 2014, a randomized, multicenter, Phase II study investigated the efficacy and safety of the combination of erlotinib and Bev compared with erlotinib alone in patients with nonsquamous NSCLC with activating EGFR mutation-positive disease..$^{59}$ The authors found that the combination strategy was more favorable in terms of PFS than the monotherapy strategy. Therefore, a larger Phase III trial of this regimen is warranted.

The advent of novel immunotherapies with recent success in melanoma patients has increased interest in immunotherapy for other solid tumors, including NSCLC. Therefore, in the near future, trials of immune checkpoint inhibitors that target the programmed cell death receptor and its ligand (nivolumab and pembrolizumab) and an immune checkpoint inhibitor that targets cytotoxic T-lymphocyte-associated antigen 4 (ipilimumab) will be performed and will examine these drugs in combination with other targeted therapies and as monotherapies in the specific EGFR-mutated and ALK-rearranged NSCLC subtype. Finally, although other gene rearrangements have recently been identified (such as ROS1 proto-oncogene receptor tyrosine kinase [ROS1] and ret proto-oncogene
[RET]) that are susceptible to targeted therapies, their roles in cancer treatment are unclear and require future trials for clarification. ${ }^{60-63}$

\section{Detection of EGFR mutations and ALK rearrangement}

An important limiting factor for adequate characterization of metastatic NSCLC is the small quantity of tumor cells available for molecular analysis, and this may reduce the use of targeted therapies in NSCLC patients. ${ }^{64}$ The ideal method for performing a molecular analysis is to analyze a biopsy specimen; in fact, using a histologic sample allows for the formation of paraffin-embedded histologic slides and the selection of an area with at least $50 \%$ tumor cells for analysis. Unfortunately, one-third of primary NSCLC diagnoses are performed on cytologic samples, and usually no other biopsy materials are available for molecular analyses. ${ }^{65-68}$ Many studies have demonstrated that cytologic material is suitable for EGFR mutation detection and for the EML4-ALK FISH test. ${ }^{68-73}$ Unfortunately, cytologic material is often the only available diagnostic biologic tool.

To avoid the problem of the paucity of materials for molecular analysis, some alternate approaches have been investigated. First is the analysis of DNA extracted from plasma/serum or from circulating tumor cells. Second, some authors have tried to detect EGFR mutations in serum. ${ }^{74-78}$ However, no study has reported definitive evidence regarding this efficacy of these alternative approaches, and the optimal sample for molecular analysis is unclear.

Finally, the third-generation EGFR-TKIs, CO-1686 and AZD9291, have demonstrated promising response rates in tumors with acquired EGFR T790M mutation in early-phase studies. Additionally, ceritinib has been shown to have efficacy in overcoming some common crizotinib resistance mutations. These studies underscore the importance of re-biopsy for the performance of molecular analysis at the time of disease progression in patients with EGFR or ALK SCLC to determine subsequent treatment. ${ }^{79}$ Future studies are awaited to determine the feasibility of re-biopsy in clinical practice.

\section{The distinctive nature of adenocarcinoma of the lung}

The molecular profile of adenocarcinoma of the lung is well defined ${ }^{80}$ Common mutations include EGFR, KRAS, and ALK translocation. Therapies have been developed that target these mutations. The approved agents with indications of FDA for NSCLC patients with EGFR+ ALK+ are summarized in Table 1. This highlights the distinctive nature of 
Table I Approved drugs and indications of US Food and Drug Administration (FDA) for selected NSCLC patients (EGFR+ and ALK+)

\begin{tabular}{llll}
\hline Erlotinib & Gefitinib & Afatinib & Crizotinib \\
\hline First-line treatment of & First-line of treatment & First-line treatment of & Patients with metastatic \\
patients with metastatic & of patients with NSCLC & patients with metastatic & NSCLC whose tumors \\
NSCLC whose tumors & whose tumors harbor & NSCLC whose tumors & are ALK-positive \\
have EGFR exon 19 & EGFR mutations exon 19 & have EGFR exon 19 & disease progression on \\
deletions or exon 21 & deletions or exon 21 & deletions or exon 21 & or who are intolerant \\
(L858R) substitution & L858R substitution & (L858R) substitution & to crizotinib \\
mutations & gene mutation & mutations & \\
\hline
\end{tabular}

Notes: ALK and EGFR testing are recommended for adenocarcinomas and mixed lung cancers with an adenocarcinoma component. Clinical criteria such as: young age, lack of smoking, history, small biopsy should drive EGFR mutations and ALK rearrangements in squamous cell histology.

Abbreviations: ALK, anaplastic lymphoma kinase; EGFR, epidermal growth factor receptor; NSCLC, non-small-cell lung cancer.

adenocarcinoma of the lung among all lung cancer subtypes. For example, several studies suggest that squamous NSCLC contains many genetic mutations and that EGFR mutations and ALK fusion gene rearrangement are rare in patients with squamous cell carcinoma (generally $<1 \%$ ). ${ }^{80,81}$ Therefore, with the exception of erlotinib and the immunotherapy drug nivolumab, few target therapies are available for tumors with lung cancer and squamous cell histology. ${ }^{82,83}$ Although the results of the BR21 trial of erlotinib support the use of erlotinib as a second- or third-line therapy and afatinib could be another option for the treatment of patients with squamous cell carcinoma of the lung. ${ }^{84}$ The magnitude of the benefit of these drugs is generally smaller than in patients with EGFR mutations. . $^{82,84}$

Additionally, SCLC histology is very heterogeneous in terms of somatic mutations, but targeted treatment approaches have had limited success in SCLC in clinical trials and its role is unclear. ${ }^{85,86}$ Furthermore, the incidences of EGFR mutations and ALK translocation in high-grade pulmonary neuroendocrine carcinomas (SCLC and large-cell neuroendocrine carcinoma) are very low. Therefore, according to the International Association for the Study of Lung Cancer (IASLC), ALK and EGFR testing are recommended for adenocarcinomas and mixed lung cancers with an adenocarcinoma component. It is reasonable to test for EGFR mutations and ALK rearrangements in tumors with squamous cell histology, but clinical criteria, such as young age, lack of smoking history, and small biopsy specimens, may affect the decision to perform such tests. ${ }^{87}$ Additionally, although it is not a subject of this review, we must report that patients with adenocarcinoma of the lung are the only who can be treated with the anti-angiogenetic agent Bev. ${ }^{88,89}$ Finally, chemotherapy with pemetrexed (a folate antimetabolite chemically similar to folic acid) in combination with cisplatin is only recommended as an option for the first-line treatment of patients with locally advanced or metastatic NSCLC if the tumor has been histologically confirmed to be adenocarcinoma or large-cell carcinoma. ${ }^{88-90}$

\section{Conclusion}

EGFR mutations and EML4-ALK translocation are the most clinically relevant alterations that can dictate personalized treatment in NSCLC patients. Unfortunately, less than $15 \%$ of patients with adenocarcinoma of the lung are ideal candidates for these targeted therapies because EGFR mutations and ALK rearrangements are generally mutually exclusive. ${ }^{91,92}$ Additionally, limited lung cancer specimens (biopsies and cytologic specimens) can preclude the detection of these mutations. In the near future, we will address new research and clinical trials to discover alternative sampling approaches, such as plasma- or serum-derived DNA, for molecular analysis and to discover new drugs that can overcome the resistance to anti-EGFR and EML4-ALK targeted therapies.

\section{Disclosure}

The author reports no conflicts of interest in this work.

\section{References}

1. Zeng C, Wen W, Morgans AK, Pao W, Shu XO, Zheng W. Disparities by race, age, and sex in the improvement of survival for major cancers: results from the National Cancer Institute Surveillance, Epidemiology, and End Results (SEER) Program in the United States, 1990 to 2010. JAMA Oncol. 2015;1(1):88-96.

2. Ciardiello F, Tortora G. EGFR antagonists in cancer treatment. $N$ Engl J Med. 2008;358:1160-1174.

3. Hynes NE, Lane HA. ERBB receptors and cancer: the complexity of targeted inhibitors. Nat Rev Cancer. 2005;5:341-354.

4. Lynch TJ, Bell DW, Sordella R, et al. Activating mutations in the epidermal growth factor receptor underlying responsiveness of non-small-cell lung cancer to gefitinib. N Engl J Med. 2004;350:2129-2139.

5. Paez JG, Jänne PA, Lee JC, et al. EGFR mutations in lung cancer: correlation with clinical response to gefitinib therapy. Science. 2004;304: 1497-1500.

6. Dungo RT, Keating GM. Afatinib: first global approval. Drugs. 2013;73: 1503-1515.

7. Langer CJ. Epidermal growth factor receptor inhibition in mutationpositive non-small-cell lung cancer: is afatinib better or simply newer? J Clin Oncol. 2013;31:3303-3306.

8. Riely GJ, Politi KA, Miller VA, Pao W. Update on epidermal growth factor receptor mutations in non-small cell lung cancer. Clin Cancer Res. 2006;12:7232-7241. 
9. Hirsch FR, Bunn PA Jr. EGFR testing in lung cancer is ready for prime time. Lancet Oncol. 2009;10:432-433.

10. Mitsudomi T, Yatabe Y. Epidermal growth factor receptor in relation to tumor development: EGFR gene and cancer. FEBS J. 2010;277(2): 301-308.

11. Giaccone G, Rodriguez JA. EGFR inhibitors: what have we learned from the treatment of lung cancer? Nat Clin Pract Oncol. 2005;2:554-561.

12. Cappuzzo F, Hirsch FR, Rossi E, et al. Epidermal growth factor receptor gene and protein and gefitinib sensitivity in non-small-cell lung cancer. J Natl Cancer Inst. 2005;97:643-655.

13. Pao W, Wang TY, Riely GJ, et al. KRAS mutations and primary resistance of lung adenocarcinomas to gefitinib or erlotinib. PLoS Med. 2005;2:e17.

14. Sequist LV, Yang JC, Yamamoto N, et al. Phase III study of afatinib or cisplatin plus pemetrexed in patients with metastatic lung adenocarcinoma with EGFR mutations. J Clin Oncol. 2013;31:3327-3334.

15. Rosell R, Carcereny E, Gervais R, et al. Erlotinib versus standard chemotherapy as first-line treatment for European patients with advanced EGFR mutation-positive non-small-cell lung cancer (EURTAC): a multicentre, open-label, randomised phase 3 trial. Lancet Oncol. 2012; 13:239-246.

16. Cappuzzo F, Jänne PA, Skokan M, et al. MET increased gene copy number and primary resistance to gefitinib therapy in non-small-cell lung cancer patients. Ann Oncol. 2009;20(2):298-304.

17. Yasuda H, Kobayashi S, Costa DB. EGFR exon 20 insertion mutations in non-small-cell lung cancer: preclinical data and clinical implications. Lancet Oncol. 2012;13(1):e23-e31. doi:10.1016/S14702045(11)70129-2. Epub 2011 Jul 19. Review. Erratum in: Lancet Oncol. 2011;12(13):1182.

18. Sequist LV, Waltman BA, Dias-Santagata D, et al. Genotypic and histological evolution of lung cancers acquiring resistance to EGFR inhibitors. Sci Transl Med. 2011;3:75ra26.

19. Pao W, Miller VA, Politi KA, et al. Acquired resistance of lung adenocarcinomas to gefitinib or erlotinib is associated with a second mutation in the EGFR kinase domain. PLoS Med. 2005;2:e73.

20. Rosell R, Molina MA, Costa C, et al. Pretreatment EGFR T790M mutation and BRCA1 mRNA expression in erlotinib-treated advanced nonsmall-cell lung cancer patients with EGFR mutations. Clin Cancer Res. 2011;17:1160-1168.

21. Engelman JA, Zejnullahu K, Mitsudomi T, et al. MET amplification leads to gefitinib resistance in lung cancer by activating ERBB3 signaling. Science. 2007;316:1039-1043.

22. Oxnard GR. Strategies for overcoming acquired resistance to epidermal growth factor receptor: targeted therapies in lung cancer. Arch Pathol Lab Med. 2012;136:1205-1209.

23. Suda K, Mizuuchi H, Maehara Y, Mitsudomi T. Acquired resistance mechanisms to tyrosine kinase inhibitors in lung cancer with activating epidermal growth factor receptor mutation - diversity, ductility, and destiny. Cancer Metastasis Rev. 2012;31:807-814.

24. Oxnard GR, Arcila ME, Sima CS, et al. Acquired resistance to EGFR tyrosine kinase inhibitors in EGFR-mutant lung cancer: distinct natural history of patients with tumors harboring the T790M mutation. Clin Cancer Res. 2011;17:1616-1622.

25. Soria JC, Wu YL, Nakagawa K, et al. Gefitinib plus chemotherapy versus placebo plus chemotherapy in EGFR-mutation-positive non-small-cell lung cancer after progression on first-line gefitinib (IMPRESS): a phase 3 randomised trial. Lancet Oncol. 2015. pii: S1470-2045(15)00121-7.

26. Gainor JF, Shaw AT. Emerging paradigms in the development of resistance to tyrosine kinase inhibitors in lung cancer. J Clin Oncol. 2013;31: 3987-3996.

27. Kwak EL, Sordella R, Bell DW, et al. Irreversible inhibitors of the EGF receptor may circumvent acquired resistance to gefitinib. Proc Natl Acad Sci U S A. 2005;102:7665-7670.

28. Jänne PA, Boss DS, Camidge DR, et al. Phase I dose-escalation study of the pan-HER inhibitor, PF299804, in patients with advanced malignant solid tumors. Clin Cancer Res. 2011;17(5):1131-1139.
29. Miller VA, Hirsh V, Cadranel J, et al. Afatinib versus placebo for patients with advanced, metastatic non-small-cell lung cancer after failure of erlotinib, gefitinib, or both, and one or two lines of chemotherapy (LUX-Lung 1): a phase $2 \mathrm{~b} / 3$ randomised trial. Lancet Oncol. 2012;13(5):528-538. Erratum in: Lancet Oncol. 2012;13(5):e186.

30. Sequist LV, Besse B, Lynch TJ, et al. Neratinib, an irreversible panErbB receptor tyrosine kinase inhibitor: results of a phase II trial in patients with advanced non-small-cell lung cancer. J Clin Oncol. 2010; 28(18):3076-3083.

31. Sequist LV, Soria JC, Goldman JW, et al. Rociletinib in EGFR-mutated non-small-cell lung cancer. $N$ Engl J Med. 2015;372(18):1700-1709.

32. Jänne PA, Yang JC, Kim DW, et al. AZD9291 in EGFR inhibitorresistant non-small-cell lung cancer. $N$ Engl J Med. 2015;372(18): 1689-1699.

33. Mano H. Non-solid oncogenes in solid tumors: EML4-ALK fusion genes in lung cancer. Cancer Sci. 2008;99:2349-2355.

34. Palmer RH, Vernersson E, Grabbe C, et al. Anaplastic lymphoma kinase: signalling in development and disease. Biochem J. 2009;420: 345-361.

35. Soda M, Choi YL, Enomoto M, et al. Identification of the transforming EML4-ALK fusion gene in non-small cell lung cancer. Nature. 2007; 448:561-566.

36. Sasaki T, Rodig SJ, Chirieac LR, et al. The biology and treatment of EML4-ALK non-small cell lung cancer. Eur J Cancer. 2010;46: $1773-1780$

37. Takeuchi K, Choi YL, Togashi Y, et al. KIF5B-ALK, a novel fusion oncokinase identified by an immunohistochemistry-based diagnostic system for ALK positive lung cancer. Clin Cancer Res. 2009;15: 3143-3149.

38. Hernandez L, Pinyol M, Hernandez S, et al. TRK-fused gene (TFG) is a new partner of ALK in anaplastic large cell lymphoma producing two structurally different TFG-ALK translocations. Blood. 1999; 94(9):3265-3268

39. Gridelli C, Peters S, Sgambato A, Casaluce F, Adjei AA, Ciardiello F. ALK inhibitors in the treatment of advanced NSCLC. Cancer Treat Rev. 2014;40(2):300-306

40. Gupta R, Dastane AM, McKenna R Jr, Marchevsky AM. The predictive value of epidermal growth factor receptor tests in patients with pulmonary adenocarcinoma: review of current 'best evidence' with meta-analysis. Hum Pathol. 2009;40:356-365.

41. Camidge DR, Kono SA, Flacco A, et al. Optimizing the detection of lung cancer patients harboring anaplastic lymphoma kinase (ALK) gene rearrangements potentially suitable for alk inhibitor treatment. Clin Cancer Res. 2010;16:5581-5590.

42. Shaw AT, Yeap BY, Mino-Kenudson M, et al. Clinical features and outcome of patients with non-small-cell lung cancer who harbor EML4ALK. J Clin Oncol. 2009;27:4247-4253.

43. Takahashi T, Sonobe M, Kobayashi M, et al. Clinicopathologic features of non small-cell lung cancer with EML4-ALK fusion gene. Ann Surg Oncol. 2010;17:889-897.

44. Wong DW, Leung EL, So KK, et al. The EML4-ALK fusion gene is involved in various histologic types of lung cancers from nonsmokers with wild-type EGFR and KRAS. Cancer. 2009;115:1723-1733.

45. Zhang X, Zhang S, Yang X, et al. Fusion of EML4 and ALK is associated with development of lung adenocarcinomas lacking EGFR and KRAS mutations and is correlated with ALK expression. Mol Cancer. 2010;9:188.

46. Kwak EL, Bang YJ, Camidge DR, et al. Anaplastic lymphoma kinase inhibition in non-small-cell lung cancer. N Engl J Med. 2010;363: 1693-1703.

47. Shaw AT, Kim DW, Nakagawa K, et al. Crizotinib versus chemotherapy in advanced ALK-positive lung cancer. $N$ Engl J Med. 2013;368: 2385-2394

48. Solomon BJ, Mok T, Kim DW, et al; PROFILE 1014 Investigators. First-line crizotinib versus chemotherapy in ALK-positive lung cancer. N Engl J Med. 2014;371(23):2167-2177. 
49. Sørensen JB, Hansen HH, Hansen M. Brain metastases in adenocarcinoma of the lung: frequency, risk groups, and prognosis. J Clin Oncol. 1988;6:1474-1480.

50. Sasaki T, Okuda K, Zheng W, et al. The neuroblastoma-associated F1174L ALK mutation causes resistance to an ALK kinase inhibitor in ALK-translocated cancers. Cancer Res. 2010;70:10038-10043.

51. Choi YL, Soda M, Yamashita Y, et al. EML4-ALK mutations in lung cancer that confer resistance to ALK inhibitors. NEngl J Med. 2010;363: 1734-1739.

52. Doebele RC, Pilling AB, Aisner DL, et al. Mechanisms of resistance to crizotinib in patients with ALK gene rearranged non-small cell lung cancer. Clin Cancer Res. 2012;18(5):1472-1482.

53. Katayama R, Shaw AT, Khan TM, et al. Mechanisms of acquired crizotinib resistance in ALK-rearranged kung cancers. Sci Transl Med. 2012;4(120):120ra17.

54. Doebele RC, Pilling AB, Aisner DL, et al. Mechanisms of resistance to crizotinib in ALK gene rearranged non-small cell lung cancer. Clin Cancer Res. 2014;18:1472-1482.

55. Shaw AT, Kim DW, Mehra R, et al. Ceritinib in ALK-rearranged nonsmall-cell lung cancer. N Engl J Med. 2014;370:1189-1197.

56. Seto T, Kiura K, Nishio M, et al. CH5424802 (RO5424802) for patients with ALK-rearranged advanced non small cell lung cancer (AF-001JP study): a single-arm, open-label, phase 1-2 study. Lancet Oncol. 2013 14(7):590-598.

57. Iragavarapu C, Mustafa M, Akinleye A, et al. Novel ALK inhibitors in clinical use and development. J Hematol Oncol. 2015;8(1):17.

58. Petrioli R, Francini E, Fiaschi AI, et al. Switch maintenance treatment with oral vinorelbine and bevacizumab after induction chemotherapy with cisplatin, gemcitabine and bevacizumab in patients with advanced non-squamous non-small cell lung cancer: a phase II study. Med Oncol. 2015;32(4):134.

59. Seto T, Kato T, Nishio M, et al. Erlotinib alone or with bevacizumab as first-line therapy in patients with advanced non-squamous non-smallcell lung cancer harbouring EGFR mutations (JO25567): an open-label, randomised, multicentre, phase 2 study. Lancet Oncol. 2014;15(11): 1236-1244. Erratum in: Lancet Oncol. 2014;15(11):e475.

60. Drilon A, Wang L, Hasanovic A, et al. Response to cabozantinib in patients with RET fusion-positive lung adenocarcinomas. Cancer Discov. 2013;3:630-635.

61. Bergethon $\mathrm{K}$, Shaw AT, Ou SH, et al. ROS1 rearrangements define a unique molecular class of lung cancers. J Clin Oncol. 2012;30:863-870.

62. Ou SH, Tan J, Yen Y, Soo RA. ROS1 as a 'druggable' receptor v tyrosine kinase: lessons learned from inhibiting the ALK pathway. Expert Rev Anticancer Ther. 2012;12:447-456.

63. Takeuchi K, Soda M, Togashi Y, et al. RET, ROS1 and ALK fusions in lung cancer. Nat Med. 2012;18:378-381.

64. Ulivi P, Zoli W, Capelli L, Chiadini E, Calistri D, Amadori D. Target therapy in NSCLC patients: relevant clinical agents and tumour molecular characterisation. Mol Clin Oncol. 2013;1(4):575-581.

65. Gu P, Zhao YZ, Jiang LY, Zhang W, Xin Y, Han BH. Endobronchial ultrasound-guided transbronchial needle aspiration for staging of lung cancer: a systematic review and meta-analysis. Eur J Cancer. 2009; 45:1389-1396.

66. Annema JT, Versteegh MI, Veseliç M, et al. Endoscopic ultrasound added to mediastinoscopy for preoperative staging of patients with lung cancer. JAMA. 2005;294:931-936.

67. Tournoy KG, Rintoul RC, van Meerbeeck JP, et al. EBUS-TBNA for the diagnosis of central parenchymal lung lesions not visible at routine bronchoscopy. Lung Cancer. 2009;63:45-49.

68. Chen JT, Lane MA, Clark DP. Inhibitors of the polymerase chain reaction in Papanicolaou stain. Removal with a simple destaining procedure. Acta Cytol. 1996;40:873-877.

69. Smith GD, Chadwick BE, Willmore-Payne Ca, Bentz JS. Detection of epidermal growth factor receptor gene mutations in cytology specimens from patients with non-small cell lung cancer utilising high-resolution melting amplicon analysis. J Clin Pathol. 2008;61:487-493.
70. Smouse JH, Cibas ES, Jänne PA, Joshi VA, Zou KH, Lindeman NI. EGFR mutations are detected comparably in cytologic and surgical pathology specimens of nonsmall cell lung cancer. Cancer. 2009;117: 67-72.

71. Savic S, Tapia C, Grilli B, et al. Comprehensive epidermal growth factor receptor gene analysis from cytological specimens of non-small-cell lung cancers. Br J Cancer. 2008;98:154-160.

72. Ulivi P, Romagnoli M, Chiadini E, et al. Assessment of EGFR and $\mathrm{K}$-ras mutations in fixed and fresh specimens from transesophageal ultrasound-guided fine needle aspiration in non-small cell lung cancer patients. Int J Oncol. 2012;41:147-152.

73. Ulivi P, Zoli W, Chiadini E, et al. EGFR and K-ras mutations in cytologic samples from fine-needle aspirates in NSCLC patients. Eur Respir J. 2012;40:267-269.

74. Kimura H, Kasahara K, Kawaishi M, et al. Detection of epidermal growth factor receptor mutations in serum as a predictor of the response to gefitinib in patients with non-small-cell lung cancer. Clin Cancer Res. 2006;12:3915-3921.

75. Maheswaran S, Sequist LV, Nagrath S, et al. Detection of mutations in EGFR in circulating lung-cancer cells. $N$ Engl J Med. 2008;359: 366-377.

76. He C, Liu M, Zhou C, et al. Detection of epidermal growth factor receptor mutations in plasma by mutant-enriched PCR assay for prediction of the response to gefitinib in patients with non-small-cell lung cancer. Int J Cancer. 2009;125:2393-2399.

77. Rosell R, Moran T, Queralt C, et al. Screening for epidermal growth factor receptor mutations in lung cancer. $N$ Engl J Med. 2009;361: 958-967.

78. Brevet M, Johnson ML, Azzoli CG, Ladanyi M. Detection of EGFR mutations in plasma DNA from lung cancer patients by mass spectrometry genotyping is predictive of tumor EGFR status and response to EGFR inhibitors. Lung Cancer. 2011;73:96-102.

79. Govindan R. Overcoming resistance to targeted therapy for lung cancer. N Engl J Med. 2015;372(18):1760-1761.

80. Cancer Genome Atlas Research Network. Comprehensive molecular profiling of lung adenocarcinoma. Nature. 2014;511(7511):543-550. Erratum in: Nature. 2014;514(7521):262. Rogers, K [corrected to Rodgers, K].

81. Hammerman PS, Sos ML, Ramos AH, et al. Mutations in the DDR2 kinase gene identify a novel therapeutic target in squamous cell lung cancer. Cancer Discov. 2011;1(1):78-89.

82. Shepherd FA, Rodrigues Pereira J, et al; National Cancer Institute of Canada Clinical Trials Group. Erlotinib in previously treated non-smallcell lung cancer. N Engl J Med. 2005;353(2):123-132.

83. Brahmer J, Reckamp KL, Baas P, et al. Nivolumab versus docetaxel in advanced squamous-cell non-small-cell lung cancer. $N$ Engl J Med. 2015;373(2):123-135.

84. Soria JC, Felip E, Cobo M, et al; LUX-Lung 8 Investigators. Afatinib versus erlotinib as second-line treatment of patients with advanced squamous cell carcinoma of the lung (LUX-Lung 8): an open-label randomised controlled phase 3 trial. Lancet Oncol. 2015. pii: S14702045(15)00006-6.

85. Arcaro A. Targeted therapies for small cell lung cancer: where do we stand? Crit Rev Oncol Hematol. 2015;95(2):154-164.

86. Petrioli R, Roviello G, Laera L, et al. Cisplatin, etoposide, and bevacizumab regimen followed by oral etoposide and bevacizumab maintenance treatment in patients with extensive-stage small cell lung cancer: a single-institution experience. Clin Lung Cancer. 2015. pii: S1525-7304(15)00137-0.

87. Molecular Testing Guideline for Selection of Lung Cancer Patients for EGFR and ALK Tyrosine Kinase Inhibitors: Summary of Recommendations. International Association for the Study of Lung Cancer (IASLC); April 2013.

88. Sandler A, Gray R, Perry MC, et al. Paclitaxel-carboplatin alone or with bevacizumab for non-small-cell lung cancer. N Engl J Med. 2006; $355: 2542-2550$ 
89. Reck M, von Pawel J, Zatloukal P, et al; BO17704 Study Group. Phase III trial of cisplatin plus gemcitabine with either placebo or bevacizumab as first-line therapy for nonsquamous nonsmall-cell lung cancer: AVAil. J Clin Oncol. 2009;27:1227-1234.

90. Scagliotti GV, Parikh P, Von Pawel J, et al. Phase III study comparing cisplatin plus gemcitabine with cisplatin plus pemetrexed in chemotherapy-naive patients with advanced-stage non-small-cell lung cancer. J Clin Oncol. 2008;26:3543-3551.
91. Gainor JF, Varghese AM, Ou SH, et al. ALK rearrangements are mutually exclusive with mutations in EGFR or KRAS: an analysis of 1,683 patients with non-small cell lung cancer. Clin Cancer Res. 2013;19: 4273-4281.

92. Takahashi T, Sonobe M, Kobayashi M, et al. Clinicopathologic features of non-small-cell lung cancer with EML4-ALK fusion gene. Ann Surg Oncol. 2010;17:889-897.

\section{Publish your work in this journal}

OncoTargets and Therapy is an international, peer-reviewed, open access journal focusing on the pathological basis of all cancers, potential targets for therapy and treatment protocols employed to improve the management of cancer patients. The journal also focuses on the impact of management programs and new therapeutic agents and protocols on

\section{Dovepress}

patient perspectives such as quality of life, adherence and satisfaction. The manuscript management system is completely online and includes a very quick and fair peer-review system, which is all easy to use. Visit http://www.dovepress.com/testimonials.php to read real quotes from published authors. 